Trans/Form/Ação, São Paulo, v. 14, p. 73-91, 1991.

\title{
CONCEITOS E ESTRUTURA MENTAL
}

\author{
Marcos Barbosa de OLIVEIRA*
}

RESUMO: $O$ objetivo da palestra foi o de apresentar um apanhado sucinto da historia das investigações sobre conceitos nas últimas decadas, com isso contribuindo para a divulgação da Ciência Cognitiva. $O$ episódio central dessa história é a guinada resultante das pesquisas realizadas por Eleanor Rosch e outros, a partir do inicio dos anos setenta. Estas pesquisas colocam em cheque a CONCEPÇĀO CLÁSSICA DE CONCEITOS (caracterizada na primeira parte da exposição). O fato de que o abandono da concepção clássica não é uma alternativa viável, dá origem ao que chamamos de PROBLEMA DA CONCILIAÇĀO, ou seja, o de compatibilizar a concepção clássica com as descobertas modernas. A apresentação se encerra com algumas sugestões para a solução do problema.

UNITERMOS: Conceitos; Ciência Cognitiva; Eleanor Rosch; protótipo; categoria básica.

\section{INTRODUÇĀO}

A apresentação que vou fazer hoje tem por tema, como o diz o título, conceitos e estrutura mental. Este título na verdade é meio tendencioso, pois coloca os dois elementos - conceitos e estrutura mental - em pé de igualdade, e assim sugere que vou dedicar tanta atenção a um como a outro. O que vai ocorrer de fato é que vou falar bastante de conceitos e só um pouquinho, no fim, de estrutura mental.

Vou começar esboçando o roteiro, o itinerário do percurso que pretendo fazer com vocês.

Inicialmente vou delinear uma caracterização de que chamarei de concepção clássica de conceitos. Esta é a concepção que vigorou na Filosofia e na Lógica pelo menos desde Aristóteles, e até pouco tempo atrás. Seu núcleo é a idéia de que um conceito corresponde a um conjunto de propriedades necessárias e suficientes. Por exemplo, para ser um homem - segundo a definição de Aristóteles, é claro - uma entidade deve possuir as propriedades de ser animal e racional, e é isto que individualiza, que define o conceito de homem.

* Departamento de Filosofia da Educação e Ciências da Educação - Faculdade de Educação - USP - São Paulo - SP. 
Pois bem, a partir da década de 70 são realizadas inúmeras pesquisas empíricas na Psicologia e na Antropologia a respeito da natureza dos conceitos. Estas pesquisas estabelecem solidamente que os conceitos - em termos de realidade psicológica - não correspondem à concepção clássica. É sobre estas pesquisas que vou falar na segunda parte de minha exposição.

$\mathrm{Na}$ terceira parte vou discutir o conflito entre a concepção clássica e as descobertas modernas. Vou argumentar que a alternativa mais 6 bvia, qual seja, a de abandonar a concepção clássica, não é viável, o que vai então nos deixar com um problema, a saber, o de compatibilizar a concepção clássica de conceitos com as descobertas modernas. Vou chamá-lo de problema da conciliação.

O problema da conciliação constitui a questão central, o cerne de minha exposição. Na quarta e última parte vou primeiro explicar uma solução que já foi proposta, depois expressar minha opinião em relação a ela, ou seja, a de que esta solução aponta na direção certa, porém não vai longe o suficiente. Por último, vou fazer um esboço muito sumário daquilo que me parece constituir a abordagem correta para o problema da conciliação. E é só neste finalzinho que vai aparecer a noção de estrutura mental.

Esta última parte corresponde ao que julgo original, àquilo que seria minha contribuição ao debate. Digo "seria" porque a descrição de minha proposta vai ser, como disse, extremamente sucinta, e também porque não me sinto ainda plenamente em condições de defendê-la. Apresentar esta proposta não $\epsilon$, entretanto, o objetivo principal de minha exposição. Meu propósito é mais modesto, $€$ apenas o de divulgar, de tornar mais conhecido todo este debate que está em curso hoje a respeito da natureza dos conceitos. Com isto espero também estar contribuindo para a divulgação da Ciência Cognitiva - uma vez que esta tradição de pesquisa sobre conceitos constitui um exemplo bem tŕpico do trabalho que se faz na nova disciplina conhecida pelo nome - talvez não muito apropriado - de "Ciência Cognitiva".

\section{A CONCEPÇĀo CLÁSSICA DE CONCEITOS}

Comecemos então. Gostaria em primeiro lugar de frisar que esta expressão "concepção clássica de conceitos" não é de minha autoria; ela foi introduzida por Smith e Medin no livro Categories and Concepts, de 1981. Minha caracterização da concepção clássica não é entretanto idêntica à deles; $́$ suficientemente semelhante, por outro lado, para que se justifique o uso do mesmo nome.

A concepção clássica, como já disse, tem por núcleo e noção de propriedades necessárias e suficientes. São estas que determinam a aplicabilidade de um conceito: um conceito aplica-se a certa entidade se e somente se esta possuir o conjunto de propriedades que $o$ individualiza.

A lista de propriedades constitui a definição de um conceito. Cada propriedade, por sua vez, corresponde a um outro conceito, caracterizado por uma outra lista de propriedades, e assim por diante. Esta seqüência pode dar origem a uma regressão infinita; para evitá-la postula-se a existência de uma classe de conceitos primitivos, correspondentes a propriedades atômicas, indecomponf́reis. 
A este núcleo da concepção clássica de conceitos acrescenta-se uma idéia de precisão, de digitalidade: ou bem um conceito aplica-se a uma entidade, ou bem não se aplica; não há meio termo, e se duas entidades quaisquer são exemplares de um conceito, elas o são a igual título, ou seja, um conceito não se aplica mais, ou melhor a uma entidade que a qualquer outra; ou ainda, em outras palavras, não há melhores ou piores representantes de um conceito.

Outro aspecto da concepção clássica é que, de acordo com ela, os conceitos podem se organizar em taxonomias. O exemplo mais paradigmático de taxonomia é o sistema de classificação biológica - cujos níveis correspondem a: especies, gêneros, famnlias, ordens, etc. Do ponto de vista cognitivo, nenhum nível de uma taxonomia possui uma especificidade intrínseca, ou seja, um nfvel distingue-se dos outros apenas por sua posição na hierarquia, e não por alguma particularidade cognitiva. Isto vai ficar mais claro depois, quando indicarmos a maneira pela qual esta idéia tem sido contestada.

A concepção clássica, como já dissemos, foi a que predominou ao longo de quase toda a história da Filosofia e da Lógica. Com algum exagero, pode-se dizer que ela foi na verdade a única concepção bem desenvolvida que existia, e em um número enorme de teorizações dos mais diferentes tipos ela aparece simplesmente como um pressuposto auto-evidente, não questionado e nem ao menos explicitado. Naturalmente não quero dizer com isso que nunca tenha havido controversias a respeito da natureza dos conceitos; na verdade, toda a polêmica sobre os universais que vem desde Platão pode ser entendida como uma disputa sobre a natureza dos conceitos. Mas - de novo, possivelmente com certo exagero - o que poderfamos dizer é que isto que estou chamando de concepção clássica constituiu o terreno comum, a área de acordo implícito entre as várias partes envolvidas nestas seculares controvérsias.

Foi apenas em meados deste século, a meu ver, que a concepção clássica começou a ser colocada em questão. O pioneiro nisso foi Wittgenstein - mas sobre Wittgenstein falarei mais tarde. $O$ desafio à concepção clássica que me interessa mais de perto é o que veio de observações empíricas, de experimentos na Psicologia, e, secundariamente, na Antropologia. Antes de falar desses experimentos gostaria, entretanto, de caracterizar a posição da concepção clássica de conceitos no interior da Psicologia.

Já afirmei que a concepção clássica foi a predominante ao longo de quase toda a história da Filosofia e da Lógica; pois bem, o mesmo vale para a Psicologia. Até a década de 70 a concepção clássica esteve firmemente arraigada na Psicologia, tanto na Cognitiva quanto na behaviourista. Para dar uma idéia mais precisa, vou descrever agora para vocês um certo experimento psicológico, um experimento típico dos estudos sobre conceitos realizados na tradição cognitivista pelo menos desde a década de 20 até a década de 60 de nosso século. (Quanto à tradição behaviourista, veja-se por exemplo 12, p. 285-6)

Gostaria então que vocês imaginassem um conjunto de cartões, de cartas, como as de baralho, havendo em cada carta uma figura. Os atributos dessas figuras variam ao longo de certas dimensões. Quanto à forma, por exemplo, a figura pode ser um circulo, 
um quadrado, uma cruz, etc.; quanto à cor, pode ser, digamos, vermelha, amarela ou verde; e quanto ao tamanho, pequena, média ou grande.

Este é um experimento sobre a formação de conceitos, e o que são então os conceitos neste contexto? Em completo acordo com a concepção clássica, os conceitos são concebidos como conjuntos de atributos. No caso, o que temos não são conceitos pre-existentes, naturais, por assim dizer, mas conceitos artificiais, inventados apenas como parte do experimento. Por exemplo, o conceito cabel pode corresponder aos atributos ctrculo e verde. Ou seja, uma figura é cabel se e somente se possuir a propriedade de ser ćrculo e a propriedade de ser verde, podendo, quanto ao tamanho, ser pequena, média ou grande. A concordância da idéia de conceito que serve de base ao experimento com a concepção clássica, em seus vários aspectos, não precisa ser enfatizada: ela salta aos olhos.

E qual é então o experimento? A tarefa do sujeito, ou seja, da cobaia do experimento é formar o conceito de "cabel", ou, em outras palavras, descobrir o significado do termo "cabel". O experimentador vai apresentando as cartas, e para cada uma delas o sujeito declara se se trata de uma carta "cabel" ou não. Depois de cada tentativa, o experimentador informa ao sujeito se a resposta está certa ou errada, at $€$ que o sujeito passe a acertar consistentemente, o que sinaliza a descoberta do conceito de "cabel". Trata-se, na verdade, de um tipo de problema que, muitos de vocês terão notado, ocorre freqüentemente em testes de inteligência. Por meio de variações deste esquema básico, os psicólogos puderam estudar relações entre os vários fatores que intervêm no experimento, tais como: o número de tentativas necessárias para o descobrimento do conceito, em função da idade do sujeito, de seu nível de escolaridade, da complexidade dos conceitos, das estratégias utilizadas, etc.

Experimentos deste tipo foram realizados por Vygotsky e seus colaboradores nas décadas de 20 e 30 (CF. 21, cap. 5.); na década de 50 um longo e meticuloso estudo foi levado a cabo por rês pesquisadores americanos - Bruner, Goodnow e Austin - e publicado no livro que se tornou um clássico na área, o livro que tem por título $A$ Study of Thinking (Um Estudo sobre o Pensamento) (4). Muito de interessante foi descoberto nestas pesquisas; o que eu diria, entretanto, é que elas têm certas limitações e defeitos fundamentais os quais decorrem precisamente do fato de que elas tomam a concepção clássica de conceitos como um pressuposto básico, não questionado. Meu objetivo, entretanto, não é o de desenvolver esta crítica: toda esta tradição de pesquisa sobre conceitos foi mencionada apenas para salientar a profundidade da ruptura que representou o novo paradigma que se instaura a partir do inf́cio da década de 70.

\section{AS DESCOBERTAS MODERNAS}

Antes de iniciar a descrição propriamente dita dessas pesquisas mais recentes, alguns prolegômenos são ainda necessários. 
Em primeiro lugar, gostaria de frisar que a quantidade dessas pesquisas $\varepsilon$ muito grande, $\varepsilon$ enorme a literatura que descreve seus resultados, e representa as inúmeras controversias que têm surgido. De fato, a questão da natureza dos conceitos tem sido um dos principais focos de investigação nos últimos tempos não apenas na Psicologia, mas em todo o domf́nio multidisciplinar da Ciência Cognitiva. Ou seja, não apenas psicólogos, mas também filósofos, lingüistas, especialistas em Inteligência Artificial, antropólogos e neurologistas têm se interessado bastante pela questão dos conceitos. Não pretendo aqui naturalmente recapitular toda esta literatura (Nota A). Meu proposito E bem mais modesto, pretendo apenas descrever sumariamente alguns dos experimentos mais significativos, do ponto de vista da concepção clássica de conceitos, ou mais precisamente, alguns dos experimentos que contrariam, que colocam em cheque a concepção clássica. Mesmo com esta restrição de ponto de vista, meu levantamento estará longe de ser exaustivo. Esta é afinal uma exposição introdutória, muito genérica, e pela limitação de tempo teria que passar por cima de muitas questões, de muitas indagações que poderiam ser levantadas.

O significado principal deste novo paradigma de pesquisa sobre conceitos foi, de fato, o de colocar em cheque a concepção clássica. Esta, entretanto, não foi sua motivação inicial.

O nome mais importante associado ao novo paradigma $\varepsilon$ o da pesquisadora americana Eleanor Rosch. Rosch foi orientanda de Roger Brown, um psicólogo e lingüista muito influente, e Brown por sua vez trabalhou bastante em colaboração com Eric Lenneberg - cujo interesse maior residia nos aspectos biologicos da linguagem (Lenneberg é o autor do clássico Biological Foundations of Language (14)). É com Brown e Lenneberg que a história que nos interessa tem inf́cio, na década de 50. Havia nesta época tanto entre lingüistas quanto entre psicólogos e antropólogos um grande interesse pela Hipotese de Sapir-Whorf. Whorf, como vocês devem lembrar, foi um lingüista que se dedicou ao estudo das línguas indŕgenas da América do Norte e, influenciado pelas idéias de seu mestre Sapir, veio a formular a hipótese que leva seus nomes - e é também conhecida como o Princtpio da Relatividade Lingǘstica -e este o nome que vou usar daqui por diante. Esse princrpio diz, grosso modo, que a estrutura cognitiva de um ser humano depende fortemente de sua língua materna, ou, em termos menos técnicos, que a língua materna condiciona a maneira como uma pessoa vê - e vive - o mundo. Para tornar um pouco mais nftido o espírito do Prinçpio da Relatividade Lingürstica, vou citar duas passagens, cada uma de um desses autores. A primeira ê de Whorf:

"Dissecamos a natureza em cortes prescritos por nossas línguas maternas. As categorias e tipos que isolamos do mundo dos fenômenos, não os encontramos por eles nos saltarem aos olhos; ao contrário, o mundo apresenta-se num fluxo caleidoscópico de impressões que deve ser organizado por nossas mentes - e isto quer dizer, em grande parte pelos sistemas lingüisticos que temos em nossas mentes. Seccionamos a natureza, organizamo-la em conceitos, e atriburmos significados da maneira como o fazemos em grande medida porque somos parte de um acordo para organizá-la assim - um acordo que 
vigora para toda a comunidade lingürstica e e codificada nos padrões de nossa língua. (...) nenhum indivíduo é livre para descrever a natureza com absoluta imparcialidade, mas é coagido a certos modos de interpretação mesmo quando se julga mais livre" (22, p. 213-4).

E agora a de Sapir:

“É completa ilusão imaginar que alguém se ajuste à realidade essencialmente sem o uso da linguagem, e que a linguagem $e$ apenas uma maneira idêntica de resolver problemas especfficos de comunicação ou reflexão (Nota B). O fato incontestável ê que o mundo "real" se constrói inconscientemente, em grande parte, na base dos hábitos lingürsticos do grupo. Não há duas linguagens suficientemente parecidas para que se possa considerar que representem a mesma realidade social. Os mundos em que diferentes sociedades vivem são mundos distintos, não meramente o mesmo mundo com rótulos diferentes afixados" (19, p.162) (Nota C).

Voltando então a Brown e Lenneberg: como tantos outros na época, eles tinham grandes simpatias pelo Princŕpio da Relatividade Lingürstica. Julgavam, entretanto, que este não havia ainda sido suficientemente corroborado, ou seja, que as eviḍências emṕricas aduzidas por Whorf e Sapir não bastavam para comprovar de fato sua hipótese. Teve inf́cio assim um programa de pesquisa destinado a trazer à luz tais evidências.

Os sistemas de nomenclatura de cores são um dos aspectos mais 6bvios em que linguas de diferentes famnias diferem. Por esta e outras razões, Brown e Lenneberg decidiram focalizar suas pesquisas sobre os conceitos de cor, e suas variações de língua para língua. $O$ objetivo então era o de corroborar, para este domfnio circunscrito, o Prinćpio da Relatividade Lingürstica. Desenrola-se, a partir deste ponto, uma história bastante interessante - porém bastante intrincada também - uma história que o proprio Brown relata muito bem num longo artigo publicado em 1976 - uma peça escrita em homenagem a seu colega Lenneberg, que acabara de falecer (3). Pois bem, todo este episódio - que não terei tempo de contar em detalhe - foi essencialmente uma história de quem foi buscar lã e saiu tosquiado. Explico. Embora os primeiros resultados das pesquisas aparentemente corroborassem o Prinćpio da Relatividade Lingürstica (ainda que numa versão fraca), na etapa final - e ar o trabalho de Eleanor Rosch já teve um papel crucial - ficou patente que as evidências emṕricas obtidas apontavam exatamente na direção oposta, ou seja, elas refutavam o Prinḉpio em questão. $O$ que se percebeu foi que por baixo da aparente diversidade, havia nos sistemas de nomenclatura de cores uma unidade profunda. Mais precisamente: constatou-se que o sistema de nomenclatura de cores pode variar de uma língua para outra, mas esta variação não $\varepsilon$ aleatơria, não $\varepsilon$ qualquer variação possível, mas deve obedecer a certos princípios, os quais são universais, comuns a todas as línguas humanas. Ou seja, apesar das diferenças nos conceitos de cor, a maneira como os seres humanos vivem as cores não depende em nada de fundamental de sua língua materna. 
Porém o que nos interessa mais de perto nesta história toda é que, além de contribuir para a refutação do Princŕpio da Relatividade Lingürstica, as evidências empiricas obtidas por Rosch pareciam entrar em choque também com a concepção clássica de conceitos.

A partir daf Rosch, seus colaboradores, e muitos outros depois deles, primeiro, constataram que os aspectos aparentemente adversos à concepção clássica que haviam sido detectados nos conceitos de cor apareciam também em vários outros tipos de conceitos; e segundo, estabeleceram muitos outros resultados que, de diversas maneiras, também entravam em choque com a concepção clássica.

Antes de dar inf́cio à breve descrição destas pesquisas que pretendo fazer, ainda, uma observação é necessária. Meu objetivo é relacionar todas as evidências contrárias à concepção clássica, e não apenas as descobertas por este paradigma de pesquisa do qual Rosch foi a pioneira. $O$ fato e que há observações não-sistemáticas, não "cientrficas", que, no mínimo, não se coadunam muito bem com a concepção clássica.

Considere-se, por exemplo, o requisito de digitalidade, de precisão que mencionei anteriormente como uma propriedade fundamental dos conceitos, de acordo com a concepção clássica. Numa outra passagem afirmei que esta concepção é um pressuposto implícito de quase toda a Lógica. Ocasionalmente porém encontram-se manifestações explrcitas. Quanto ao requisito de precisão, por exemplo, pode-se ler em Frege:

"No que se refere aos conceitos, temos [...] o requisito, de que, para qualquer argumento, eles tenham por valor um valor de verdade; que seja determinado, para qualquer objeto, se ele cai sob o conceito ou não. Em outras palavras: em relação a conceitos existe um requisito de delimitação precisa: se este não estivesse satisfeito, seria impossfvel estabelecer leis lógicas para eles" (8, p. 135) (Nota D).

Pois bem, não é necessário nenhum experimento psicológico para que nos convençamos de que pelo menos uma boa parte dos conceitos não satisfaz este requisito, não tem limites precisos (Nota E). O exemplo das cores é paradigmático: seguindo ao longo do espectro, encontramos tonalidades intermediárias, que não são nem uma cor nem outra. Todos os conceitos correspondentes a propriedades físicas que variam continuamente - conceitos como alto e baixo, leve e pesado, e tantos outros também estes claramente carecem de precisão, de limites bem definidos. Enfim, não e necessário insistir no óbvio; mais interessante é saber de que maneira lógicos como Frege, apesar da obviedade da vagueza dos conceitos, sustentavam o requisito de precisão. A resposta é que eles não viam grande dificuldade neste conflito, considerando a imprecisão dos conceitos simplesmente como um defeito das linguagens naturais, a qual não devia, evidentemente, ocorrer nas linguagens artificiais dos sistemas lógicos (Cf. 11, p. 162-3.). O quanto esta resposta é insatisfatória vai ficar claro a partir de quase tudo o que tenho ainda a dizer hoje. 
Outro componente da concepção clássica é a idéia de que conceitos podem ser definidos, consistindo esta definição numa lista de propriedades necessárias e suficientes. Também não e preciso realizar investigações para mostrar que, de novo, isto não é o que parece acontecer com os conceitos das linguagens naturais. Considere-se, por exemplo, o conceito de cão. Uma das propriedades definidoras deste conceito seria presumivelmente a propriedade de ser quadrúpede, de ser um animal de quatro patas. Quando porém vemos um cão que perdeu uma pata num acidente, não the negamos a natureza de cão; dizemos que se trata de um cão com três patas. Talvez se possa dizer que isto mostra apenas que ter quatro patas não $\varepsilon$ uma propriedade definidora do conceito de cão, ou, em outras palavras, que ser quadrúpede não faz parte da essência da "canidade", que corresponde apenas a um atributo acidental. O problema, porém, é que aquilo que ocorre em relação à propriedade de ter quatro patas acontece também com todas as outras candidatas possiveis ao estatuto de propriedade essencial, definidora.

Considere-se também a definição aristotélica de homem como animal racional. De novo não é diff́cil encontrar contra-exemplos. Uma pessoa insana, um louco, concebese normalmente como um ser desprovido de razão, como um ser irracional. Mas embora possamos negar aos loucos alguns dos direitos e prerrogativas dos seres humanos normais, não lhes negamos o atributo de humanidade: um louco não deixa de ser um homem, ê um homem irracional.

Enfim, a conclusão a que se chega após levantamentos sistemáticos a respeito de conceitos de vários tipos diferentes é de que, com exceção do domfnio das chamadas ciências exatas, da Matemática, especialmente, são problemáticas todas as definições que se tenta estabelecer dentro do esquema de propriedades necessárias e suficientes.

Mencionei Wittgenstein anteriormente, e a muitos de vocês esta discussão sobre a definibilidade dos conceitos deve lembrar a famosa passagem das Investigaçôes $F i$ losoficas (23), onde Wittgenstein desafia o leitor a apontar uma, que seja, propriedade comum a todos os jogos - jogos de cartas, de tabuleiro, de bola, etc. Depois de examinar e rejeitar sucessivamente várias candidatas, Wittgenstein conclui pela não existência de tal propriedade comum a todos os jogos. Então propõe que a pertinência ao conceito, neste caso, $€$ função de "uma rede complicada de semelhanças", e a esta rede ele dá o nome de semelhanças familiares (par. 66-67).

Logo a seguir nas Investigações Wittgenstein trata do tópico da precisão dos conceitos. Wittgenstein coloca-se como um defensor da imprecisão, ou seja, ele aponta sua existência nos conceitos comuns e, opondo-se explicitamente a Frege, argumenta que nem por ser impreciso um conceito deixa de ser útil (par. 71).

Não há dúvida então de que, em relação a estes dois quesitos - a definibilidade e a precisão dos conceitos - Wittgenstein foi um precursor do questionamento da 
concepção clássica. Ele na verdade foi lido, e é mencionado explicitamente por Rosch (Cf. 16, p. 99). Minha impressão, entretanto, e de que as idéias de Wittgenstein sobre conceitos foram absorvidas mais enquanto parte de uma concepção geral - ou seja, como parte de sua segunda filosofia - e menos enquanto questionamento da concepção clássica. Vários fatores que contribứram para isso podem ser apontados; não desejo, entretanto, me alongar sobre este assunto, estava querendo apenas, de maneira tão breve quanto posśvel, justificar a pouca atenção que será dispensada às idéias de Wittgenstein sobre conceitos neste trabalho. De qualquer forma, não há dúvida de que, enquanto questionamento da concepção clássica, as investigações psicológicas que passo a descrever agora tiveram um impacto muito maior que as sugestões de Wittgenstein.

Passemos agora a uma terceira característica dos conceitos, de acordo com a concepção clássica, a saber, a não existência de melhores ou piores representantes de um conceito, de representantes mais ou menos típicos. Esta caracteristica relaciona-se naturalmente com a precisão ou vagueza dos conceitos. Se um conceito não é preciso, se há casos-limite, entidades às quais um conceito nem bem se aplica nem bem não se aplica, então certamente existe uma gradação de representatividade. Podemos, entretanto, imaginar uma situação em que há casos-limite, porém na qual entre os casos centrais, não duvidosos, não haja hierarquia de representatividade. Ou seja, um conceito pode ser vago, havendo, entretanto, casos aos quais ele com certeza se aplica, de tal maneira que entre esses casos não há gradação de representatividade, são todos igualmente típicos.

Para mostrar que, mais uma vez, este aspecto da concepção clássica não se coaduna com a realidade dos conceitos, para tanto já se fazem necessárias observações e experimentos psicológicos propriamente ditos.

Podemos começar com o caso das cores. Estas pesquisas sobre os conceitos de cor foram empreendidas, como já mencionei, com o objetivo de corroborar o Princlpio da Relatividade Lingürstica, e uma das razões para isso foi a variabilidade bem conhecida dos sistemas de nomenclatura de cores nas línguas naturais. Cada língua tem um certo número de termos básicos (Nota F) para designar as cores, um número que varia de um máximo de 11 no inglês e outras línguas indo-européias, a um mínimo de dois - este é a caso da língua dos Dani, um povo da Nova Guiné que possui apenas o termo "mola" para as cores claras e quentes, e "mili" para os tons escuros e frios (p. 146). A maioria das línguas indígenas norte-americanas têm apenas um termo para designar as cores que nós distinguimos como verdes ou azuis; em muitos casos, o termo em questão $\varepsilon$ também a palavra que designa o mar (p. 130).

Pois bem, de acordo com o Prinć́pio da Relatividade Lingürstica, esta diferença entre as línguas implicaria uma diferença nas maneiras de as pessoas verem, ou viverem as cores. Mas como testar empiricamente esta afimmação? Resposta: fazendo 
experimentos em que são dadas aos sujeitos tarefas cognitivas e avaliando seu desempenho. Um dos experimentos, por exemplo, consistia no seguinte: mostrava-se ao sujeito uma amostra de cor num cartão, durante certo espaço de tempo, digamos, cinco segundos; depois esperava-se 30 segundos, e em seguida pedia-se ao sujeito para indicar qual a cor que correspondia à que lhe havia sido mostrada antes, a partir de um quadro com quarenta cores diferentes - incluindo, naturalmente, a cor mostrada no iń́cio (p. 146). A idéia então era de que a dificuldade encontrada pelo sujeito refletisse as caracterfsticas do sistema de nomenclatura de cores de sua língua materna. Por exemplo, se a cor mostrada inicialmente fosse um verde, e a coleção de 40 cores incluísse também um azul, era de se esperar que um falante de inglês tivesse mais facilidade para fazer a identificação correta do que um índio cuja língua materna não distingue o verde do azul.

Os experimentos, entretanto, para surpresa de Brown e Lenneberg, não detectaram diferença significativa alguma. Ou seja, o fato de uma língua ter um nome para determinada cor, não a toma mais facilmente reconhecivel.

O que se descobriu é que de fato existem diferenças entre as cores; algumas são mais facilmente identificáveis que outras. Ao longo de toda a gama de cores existentes, há certas regiões bem definidas em que a facilidade de reconhecimento atinge um pico. Estas regiões correspondem às chamadas cores focais, e estas são em número de 11. A constatação que contraria o Princípio da Relatividade Lingürstica é de que as cores focais não variam de língua para língua, de cultura para cultura. Elas constituem um universal cognitivo e refletem uma característica básica, estrutural, do aparelho visual humano. Esta conclusão a que os experimentos psicológicos conduzem, coaduna-se também com resultados de estudos neurofisiologicos sobre o aparelho visual humano (p. 152).

Do ponto de vista de minhas considerações sobre conceitos, entretanto, o que interessa mais é o fato de que existe uma relação entre as cores focais e os sistemas de nomenclatura de cores nas várias línguas. Não vou entrar em detalhes aqui, direi apenas, tomando o português como referência, que os falantes dessa língua consideram algumas tonalidades como mais representativas de cada cor que outras; e mais, que para cada cor há uma tonalidade relativamente bem definida que é considerada como a mais representativa de todas. Existe, portanto, um verde por excelência, um vermelho por excelência, e assim por diante. Estas tonalidades correspondem às cores focais, e constituem protótipos associados aos termos básicos de cor do português.

Chamemos de tipicalidade o fenômeno da existência de protótipos num determinado domínio conceitual (já que prototipicalidade seria longo demais). As pesquisas que acabei de relatar estabeleceram, portanto, a tipicalidade dos conceitos de cor. Este resultado, como mencionei anteriormente, foi a seguir, pela própria Eleanor Rosch, e por muitos outros pesquisadores, estendido para vários outros domínios concei- 
tuais, tais como os referentes a espécies biológicas, a artefatos - peças de mobnlia, ferramentas e veŕculos - figuras geométricas, etc (Cf. 16).

O que se verificou para todos esses casos foi, primeiro, que existe uma concordância muito grande entre as pessoas a respeito de quais são os exemplares mais ou menos representativos, mais ou menos típicos de um conceito. Quase ninguém contesta, por exemplo, a afirmação que uma vaca ou uma cabra são representantes mais tŕpicos do conceito de "mamffero" do que uma baleia, um morcego ou um tatu.

$\mathrm{O}$ que se constatou em segundo lugar foi que o grau de tipicalidade dos vários exemplares de um conceito $\varepsilon$ um fator crucial no desempenho de um número muito grande de tarefas cognitivas, tarefas estas que envolvem várias faculdades, ou funções cognitivas: a percepção, a memớia, a imaginação, etc. Infelizmente não vou ter tempo de exemplificar muito esta afirmação, nem vou descrever em detalhes os experimentos. Alguns resultados são bastante plausf́veis. Por exemplo, o tempo que uma pessoa gasta para classificar uma baleia como mamffero, é maior que o tempo necessário para a aplicação do mesmo conceito a uma vaca. Já outros resultados são bem mais surpreendentes, por exemplo, o que envolve a relação de semelhança, ou de similaridade. Estamos acostumados a pensar a relação de similaridade como simetrica, ou seja, dados dois objetos A e B, A é tão parecido, tão semelhante a B, quanto B é semelhante a A. Pois bem, experimentos - cujos detalhes não vou poder descrever agora - mostraram que há uma tendência a que os exemplares menos típicos sejam considerados mais semelhantes em relação aos mais típicos do que vice-versa. Ou seja, um morcego é considerado mais parecido com uma vaca do que uma vaca é parecida com um morcego $(16$, p. 97$)$.

Outro resultado curioso é o de que este fenômeno da tipicalidade manifesta-se até mesmo em relação ao conceito matemático de paridade - a propriedade de um número ser par ou Impar. Constatou-se - numa pesquisa de 1983 - que, por exemplo, 22 e um nứmero par mais típico que 18; 22 é por assim dizer, mais par que 18, e 7 é mais Impar que 23, e assim por diante (1).

Passemos agora ao último dos aspectos dos conceitos, de acordo com a concepção clássica, que é contestada pelas modernas descobertas psicológicas. Este é o aspecto que se refere às estruturas em que os conceitos se organizam, às taxonomias. Ao descrever a concepção clássica no início, disse que segundo ela as taxonomias têm a seguinte característica: que os nfveis de uma taxonomia distinguem-se uns dos outros apenas por sua posição na hierarquia; disse também que esta afirmação iria ficar mais clara numa ocasião posterior. Essa era a ocasião a que estava me referindo.

Para começar, é preciso introduzir outros exemplos de taxonomia. Alem do sistema de classificação biológico que já mencionei, foram estudadas várias taxonomias não-cientfficas, ou seja, jâ presentes nas linguagens naturais, no senso comum. Seja, por exemplo, o conceito de artefato, isto $\epsilon$, de objeto construfdo pelo homem. A partir 
dele existem hierarquias em que os outros nfveis correspondem a: mobflia, cadeira, cadeira de balanço; ou ao longo de outro ramo: veŕculo, carro, carro esporte; ou ainda: instrumento musical, piano, piano de cauda, e assim por diante.

Pois bem, o que as investigações dos psicólogos revelaram, para um número muito grande dessas hierarquias, foi que em cada uma delas existe um nfvel especial - que foi denominado nfvel básico por Eleanor Rosch (18). Numa taxonomia, os conceitos pertencentes ao nfvel básico são chamados de categorias básicas. Para não destoar da nomenclatura de Rosch, vou passar a usar, ao discutir este tópico, o termo categoria em vez de conceito; a mudança, entretanto, $\varepsilon$ apenas de rótulo: no presente contexto, "categoria" é um sinônimo perfeito de "conceito".

Rosch introduziu tamberm mais duas outras noções, as quais se relacionam com a de categoria básica, a saber, as noções de categorias, ou nfveis superordenados (superordinate) e subordinados (subordinate). A idéia é bem simples. Por exemplo, se "carro" é uma categoria básica, "vefculo" é uma categoria superordenada, e "carro esporte" a categoria subordinada.

Bem, mas o que são, afinal, as categorias básicas? São categorias que apresentam uma série muito grande de particularidades cognitivas. São as categorias que:

1. são aprendidas primeiro pelas crianças: "gato", por exemplo, é uma categoria básica, e é aprendida antes da categoria superordenada "animal", e antes da subordinada "gato siamês";

2. são as categorias mais rapidamente aplicadas, ou seja, o tempo médio, medido em experimentos psicológicos, que uma pessoa leva para identificar um objeto como um martelo (outra categoria básica), é menor que o tempo gasto para identificá-lo como uma ferramenta, ou como um martelo de vidraceiro;

3. correspondem em nfvel mais alto para o qual uma única imagem mental $\varepsilon$ associada à categoria como um todo;

4. correspondem em nfvel mais alto em que uma pessoa usa programas motores semelhantes para interagir com as entidades às quais o conceito se aplica.

Esta lista poderia ser, ainda, bastante alongada. Há um artigo recente de George Lakoff, onde se encontra uma lista semelhante - a qual tem nada menos que onze itens (13, p. 107). É esta abundância de particularidades cognitivas, todas elas convergindo para um mesmo nfvel de cada taxonomia, que impressiona, que faz com que a constatação da existência das categorias básicas corresponda realmente a uma genutna descoberta cientifica.

Para deixar claro que a existência das categorias básicas, no mínimo, não está prevista na concepção clássica, basta observar que na Lógica Aristotélica, que é naturalmente solidária à concepção clássica não há referência alguma a um nf́vel básico; há uma hierarquia de nfveis, porém cada um só se distingue dos demais por sua posição na hierarquia, e não por particularidades de qualquer outro tipo. 
Com isto encerro este relato extremamente sumário, infelizmente, das modernas descobertas psicológicas e antropológicas que colocaram em questão a concepção clássica de conceitos. Devo acrescentar que estas descobertas deflagraram uma atividade teórica muito vigorosa; inúmeras teorias ou concepções a respeito dos conceitos têm sido propostas, teorias e concepções que tentam dar conta, tentam explicar os fatos a respeito dos conceitos que foram estabelecidos pela pesquisa empírica (Cf., por exemplo, 20). Não é possível, portanto, falar da concepção moderna, já que existem várias. É por isso que não oponho a concepção clássica a uma concepção moderna, e sim às descobertas modernas.

\section{O PROBLEMA DA CONCILIAÇĀO}

Havfamos chegado ao ponto de onde se descortinava um conflito: de um lado a concepção clássica dos conceitos, de outro as descobertas modernas. Diante deste quadro, o lance mais óbvio seria o de abandonar a concepção clássica: se ela está em desacordo com as descobertas modernas a respeito de conceitos, e se estas - como acredito ser o caso - já foram suficientemente corroboradas para afastar qualquer dúvida razoável, então nada mais nos restaria a não ser considerar a concepção clássica como refutada, e, conseqüentemente, rejeitá-la.

Há várias razões, entretanto, que militam contra esta linha de ação. Em primeiro lugar, se a concepção clássica não tem fundamento algum no real, fica dif́cil explicar como pôde se originar, e se manter por mais de dois milênios a ilusão de que ela representaria fielmente a natureza dos conceitos.

A segunda consideração não $\varepsilon$ independente da primeira, e tem como base o fato de que a concepção clássica sustenta-se, na verdade, em certas intuições bastante universais e profundas - fato este comprovado inclusive por investigações psicologicas empiricas (Nota G).

A terceira razão, finalmente, tem a ver com a Lógica e a racionalidade. A concepção clássica, como já mencionei, é solidária a, é um pressuposto de quase toda a Lógica, tanto a aristotélica quanto a moderna (Nota H). Quanto a seu estatuto, por outro lado, a Lógica é considerada normalmente como uma disciplina do mesmo tipo que a Ética, isto $E$, uma disciplina normativa. A Lógica, no dizer de Frege, prescreve a maneira como devemos raciocinar, a maneira como devemos fazer inferências (Cf. 9, p. 4 e 128; e 7, p. 12). Ora, inferências são compostas de proposições, e proposições são formadas de conceitos; os conceitos são, por assim dizer, os átomos de que se compõem as demais entidades lógicas. Segue-se dar que podemos legitimamente caracterizar o objetivo da Lógica como sendo o de prescrever como devemos tratar os conceitos que temos em nossas mentes, e com o auxflio dos quais conhecemos o mundo. Os conceitos de que falam os lógicos, entretanto, são os correspondentes à concepção clássica. Ora, se interpretamos as descobertas modernas como estabelecendo que os conceitos que de fato temos não correspondem à concepção clássica, então todo o conteúdo normativo da Lógica torna-se vazio, torna-se inaplicável 
ao nosso raciocínio. Seria como uma doutrina ética, ou talvez uma norma de boas maneiras, que prescrevesse como devêssemos bater as asas. Que sentido faria tal norma, dado que, como é do conhecimento geral, os seres humanos não são providos de asas?

A Lógica - e aqui aparece o vínculo de minhas considerações com o tema geral dessa Jornada, ou, mais precisamente, com a idéia, também normativa, de racionalidade - a Lógica, como eu dizia, é em geral vista como estreitamente associada à razão, à racionalidade. Ser lógico é condição certamente necessária; para muitos é na verdade a condição nuclear, a condição mais essencial para que se possa atribuir a uma entidade o estatuto de ser racional. Se alguém sistematicamente comete contradições e inferências inválidas, a tendência é que ele seja considerado como irracional, como desprovido de razão.

Ora, se o abandono da concepção clássica de conceitos tem como conseqüência o esvaziamento do conteúdo normativo da Lógica, então a própria noção de racionalidade tem que passar por uma reformulação radical, não levando em conta, é claro, a alternativa de abandonar também o ideal de racionalidade.

$* \quad *$

Vimos então três razões que mostram ser inaceitável a rejeição pura e simples da concepção clássica de conceitos. Mesmo se nenhuma das três for por si só considerada conclusiva, em conjunto elas são mais que suficientes para que se procure alguma sarda para o impasse que não envolva a rejeição da concepção clássica. Chegamos assim ao problema que constitui o foco desta exposição, a saber, o problema de conciliar a concepção clássica com as descobertas modernas a respeito dos conceitos. Para facilitar a exposição, chamarei este problema de o problema da conciliação.

\section{CONCEITOS E ESTRUTURA MENTAL}

Não sou o primeiro a adotar os pontos de vista que conduzem ao problema da conciliação, outros autores já perceberam sua existência, e tentaram resolvê-lo. Em seu livro Categories and concepts, Smith e Medin tomam emprestada de Miller e Johnson-Laird (17) a idéia de que um conceito tem dois aspectos, ou facetas, a saber um cerne ("core") - ao qual estão associadas as relações de um conceito com outros -, e um procedimento de identificação ("identification procedure") que entra em cena quando a questão é aplicar ou não um conceito a uma entidade percebida através dos sentidos. A sugestão de Smith e Medin para o problema da conciliação - sugestão que se tornou bastante popular entre os psicólogos - consiste na idéia de que os aspectos clássicos e modernos dos conceitos não são, na verdade, incompatíveis, e isto porque eles se referem a facetas diferentes dos conceitos, os aspectos clássicos refletindo, naturalmente, o cerne, e os modernos o procedimento de identificação. 
Minha posição e de que a proposta de Smith e Medin aponta na direção certa, porém não vai longe o suficiente. $O$ raciocínio é o seguinte:

Os experimentos psicologicos que evidenciaram os aspectos modernos dos conceitos envolvem tarefas cognitivas que mobilizam várias faculdades mentais: a percepção, a imaginação, a memória, a inferência, a linguagem e outras. Se, à maneira de Fodor (em The Modularity of Mind (6)) postularmos, em correspondência com cada uma dessas faculdades um módulo, então teremos um núcleo, um esboço de uma teoria sobre a estrutura mental. $\mathrm{O}$ que observações não sistemáticas indicam, e os experimentos psicológicos deixam patente, é que as entidades mentais a que chamamos conceitos participam de,vários processos mentais diferentes. Tomemos, comoexemplo, o conceito de cão. Este conceito entra em cena quando vejo um ser à minha frente e o identifico como um cão, quando imagino um cão, quando me lembro de um cão, quando faço a inferência que me leva de ' $x$ é cão' a ' $x$ é quadrúpede', etc. Um pressuposto não explicito, de boa parte das investigaçóes que ja foram feitas sobre conceitos, é o de que é uma mesma entidade mental - no caso, o conceito de cão - que participa de todos estes processos. A proposta de Smith e Medin dá um primeiro passo ao atribuir dois aspectos, ou facetas, a esta entidade. Nós vamos mais longe, primeiro afirmando que, em princípio, um conceito pode ter não apenas duas, mas várias facetas, cada uma correspondendo a um processo mental, e segundo, admitindo também a possibilidade de que não se trata na verdade de várias facetas de uma mesma entidade, mas sim de várias entidades diferentes, as quais têm entre si determinadas relações de correspondência. De acordo com este ponto de vista, o conceito de cão não designa uma entidade, mas sim uma famlia de entidades mentais, cada membro correspondendo a um módulo, ou, em outras palavras, cada membro representando um modo de ser do conceito, enquanto participante de cada tipo de processo mental. Uma conseqüência evidente deste ponto de vista é o princípio segundo o qual o estabelecimento da natureza dos conceitos pressupõe uma teoria sobre a estrutura e o funcionamento da mente hwmana. Ou seja, sర podemos conhecer os membros de cada famnia de entidades mentais, que correspondem a um conceito, quando dispusermos de uma teoria que explique quantos e quais são os módulos de que se compõe a mente humana, como é o funcionamento de cada um deles, como eles se inter-relacionam, etc.

Para tornar mais inteligfvel - e mais plausfvel - minha proposta, podemos introduzir neste ponto a questão de se os animais têm ou não conceitos. Por um lado, os conceitos, por assim dizer, têm um pé na linguagem; existe no mínimo uma relação muito estreita entre um conceito e a palavra que o designa. Se considerarmos este aspecto dos conceitos como essencial, então somos levados a afirmar que os animais não têm conceitos, já que não têm o dom da linguagem (Nota I). Por outro lado, e evidente que os animais são capazes de executar tarefas cognitivas, que podem ser interpretadas muito naturalmente em termos de conceitos. Por exemplo, se um cão discrimina um osso como comestivel, e passa a roê-lo, então não e estapafúrdio afirmar que o animal aplica o conceito de comida a certo objeto. A safda do dilema consiste naturalmente em distinguir os conceitos que os animais possuem daqueles possufdos 
pelos seres humanos. Dizemos assim que os conceitos animais têm alguns, mas não todos os aspectos dos conceitos humanos; eles constituem uma versão, ou forma primitiva destes. Ao usar as expressões "conceitos animais" e "conceitos humanos", estamos falando como se o objeto de nosso discurso fosse dois tipos diferentes de uma mesma entidade; a outra alternativa é usar expressões diversas, que corresponderiam, então, a entidades diferentes - mas que teriam entre si certas relações de correspondência. Esta segunda alternativa $\varepsilon$ a adotada, por exemplo, por dois autores que trataram recentemente destas questões. Andrew Woodfield, em seu Schemas and Protoconcepts: a Two-tier Model of Concept Formation (24), usa a expressão esquemas perceptuais (perceptual schemas) par7 designar aquilo que chamamos conceitos animais, enquanto R. Bogdan, em What do we need concepts for? (2), introduz, com o mesmo objetivo, categorias comportamentais (behavioral categories). Seja qual for o nome que se lhes queira atribuir, o fato $\varepsilon$ que tais entidades estão presentes também nos seres humanos - na medida em que há tarefas cognitivas que são levadas a cabo essencialmente da mesma maneira nos homens e animais, tarefas das quais participam as categorias comportamentais (para usar a expressão de Bogdan). Notese também a relação estreita - porém não de identidade - que há entre, de um lado, a distinção cerne/procedimento de identificação, de outro a distinção conceito (propriamente dito)/categoria comportamental.

Minha proposta consiste, então, essencialmente em uma tese e um corolário. A tese $\hat{\epsilon}$ a de que um conceito $\varepsilon$ na verdade uma famflia de entidades, cada qual correspondendo a um processo mental; dela decorre o corolário segundo o qual a investigação sobre a natureza dos conceitos só pode ser realizada no contexto de uma Teoria da Estrutura Mental.

Como mencionei no iń́cio, não vou, por vários motivos, fazer a defesa dessas teses agora. Gostaria, entretanto, de concluir esta exposição com uma réplica àquela que talvez seja a primeira objeção que minhas propostas podem provocar. Um crítico poderia dizer-me o seguinte:

Você partiu de um problema relativamente simples, relativamente bem definido-o problema de conciliar a concepção clássica com as descobertas modernas - e em vez de resolvê-lo, colocou em seu lugar todo um conjunto de problemas. Ou seja, antes tínhamos apenas um tipo de entidades - os conceitos - cuja natureza precisávamos elucidar. A tarefa agora $\varepsilon$ a de esclarecer a natureza não apenas de um, mas de vários tipos de entidades, e também a natureza das relações que existem entre eles. Além disso - continuaria o critico - você remete a solução desses problemas a uma Teoria da Estrutura Mental - que $\varepsilon$ realmente um empreendimento enorme. É enorme na medida em que uma teoria como esta deve dar conta, presumivelmente, não apenas dos fatos referentes a conceitos, mas de tudo o que se sabe de essencial sobre todos os demais aspectos e funções da mente. Em resumo, na tentativa de eliminar um monstro, eu teria dado origem a vários outros, muito mais terrfveis. 
Respondo: a culpa e minha. Eu insistiria nas minhas propostas, retrucando ao crftico que se o problema da conciliação aparece como sendo muito difícil nesta abordagem, $\varepsilon$ porque ele $\varepsilon$ de fato muito dif́́cil; e se há uma perspectiva a partir da qual ele parece fácil, esta perspectiva é enganosa.

A moral da história para mim é a seguinte: que a estratégia de dividir para conquistar, a estratégia de isolar os fenômenos, que deu tão bons resultados em tantas ciências, não funciona bem em relação aos fenômenos da mente. A mente humana $€$ um sistema holístico; holístico neste sentido, de que, muito mais do que em outros domínios, e impossivel compreender as partes sem entender o todo.

\section{NOTAS}

A - Para um levantamento desta literatura, são convenientes como ponto de partida as bibliografias das obras mencionadas, a seguir. O capitulo 12 (A world categorized), do livro de Gardner (The Mind's New Science) (10), constitui uma boa introdução para o estudo das pesquisas cognitivistas sobre conceitos. Do ponto de vista da Psicologia, são bastante úteis os review articles, de Mervis e Rosch, e de Medin e Smith, ambos na Annual Review of Psychology, 1981 (16) e 1984 (15), respectivamente. Os principais aspectos filos 6 ficos do tema em pauta são tratados no número especial, dedicado a conceitos, da revista Mind and Language, que foi publicado em 1989 (ver referências a artigos de Lakoff (13) e Bogdan) (2).

B - No original ... and that language is merely an identical means of solving specific problems of communication or reflection...

C - Existe tradução brasileira, de J. Mattoso Câmara Jr., em Lingütstica como Ciência (19) (p. 20). A tradução apresentada é de minha autoria, porém não difere em nada de essencial da de Mattoso Câmara.

D - Existe tradução brasileira, de Paulo Alcoforado, em Logica e Filosofia da Linguagem (8) (p. 48). A tradução apresentada é de minha autoria, porém não difere em nada de essencial da de Paulo Alcoforado.

E - O que não significa que tais experimentos não tenham sido realizados. A imprecisão dos conceitos manifesta-se na inconsistência em sua aplicação; ou seja, ora julga-se que um conceito aplica-se, ora que não se aplica a uma determinada entidade. Esta inconsistência foi detectada experimentalmente tanto em julgamentos de sujeitos diferentes quanto em julgamentos de um mesmo sujeito, em ocasiōes diferentes. Cf. Mervis e Rosch, Categorization of Natural Objects (16), p. 101.

F - Para a noção de 'termo básico de cor', v. Brown (3), p. 141. Este texto de Brown E a fonte principal do relato que se segue no texto; as indicações de número de página entre parênteses referem-se a este artigo.

G - McNamara e Sternberg, citados por Medin e Smith (20), p. 122. 
H - As exceções são alguns ramos recentes da Lógica, particulannente os sistemas da chamada fuzzy logic. A Lógica fuzzy, entretanto pode-se dizer que faz parte do movimento de contestação da concepção clássica; seu ponto de partida é a premissa de que os conceitos têm na verdade limites imprecisos.

I - Não levando em conta, naturalmente, a tese de Fodor (em The Language of Thought (5)), segundo a qual o processamento cognitivo dos animais, tanto quanto o dos seres humanos, se dá numa linguagem do pensamento.

OLIVEIRA, M. B. de. Concepts and mental structure. Trans/Form/Ação, São Paulo, v. 14, p. 73-91, 1991.

ABSTRACT: The aim of the talk was to present a brief account of the history of investigations about concepts in the last decades, thereby contributing to the diffusion of cognitive science. The central episode in that history is the turning point that resulted from the researches carried out by Eleanor Rosch and others from the beginning of the 70's. Those researches constitute a challenge to the CLASSICAL VIEW OF CONCEPTS (which is described in the first part of the exposition). The fact that the rejection of the classical view is not a viable alternative generates what we called the PROBLEM OF CONCILIATION - that is, the problem of conciliating the classical view with the modern empirical results. The exposition ends with some suggestions towards the solution of the problem of conciliation.

KEYWORDS: Concepts; cognitive science; Eleanor Rosch; prototype; basic category.

\section{REFERÊNCIAS BIBLIOGRÁFICAS}

1. ARMSTRONG, S. L., GLEITMAN, L. R., GLEITMAN, H. What some concepts might not be. Cognition, Lausanne, v. 13, p. 263-308, 1983.

2. BOGDAN, R. What do we need concepts for? Mind and Language, Oxford, v. 4, n. 1/2, p. 17-23, 1989.

3. BROWN, R. Reference: in memorial tribute to Eric Lenneberg. Cognition, Lausanne, v. 4, p. $125-153,1976$.

4. BRUNER, J. S., GOODNOW, J., AUSTIN, G. A study of thinking. New York: Wiley, 1956.

5. FODOR, J. The language of thought. Cambridge, MA: Harvard University Press, 1975.

6. FODOR, J. The modularity of mind. Cambridge, MA:The Mit Press, 1983.

7. FREGE, G. The basic laws of arithmetic. Translated by M. Furth. Berkeley: University of California Press, 1962.

8. FREGE, G. Funktion und Begriff. In: ANGELELLI, I., ed. Kleine Schriften. Hildesheim: Georges Olms, 1967. Existe tradução brasileira: FREGE, G. Função e conceito. Trad. de Paulo Alcoforado. In: linguagem. São Paulo: Cultrix/EDUSP, 1978. - Lógica e filosofia da

9. FREGE, G. Posthumous writings. Translated by P. Long and R. White. Oxford: Blackwell, 1979. 
10. GARDNER, H. The mind's new science: a history of the cognitive revolution. New York: Basic Books, 1985.

11. HAACK, S. Philosophy of logics. Cambridge: Cambridge University Press, 1978.

12. HERRNSTEIN, R. J., LOVELAND, D. H., CABLE, C. Natural concepts in pigeons. Journal of Experimental Psychology: Animal Behavior Processes 2, Washington, v. 2, n. 4, p. 285-302, 1976.

13. LAKOFF, G. Some empirical results about the nature of concepts. Mind and Language, Oxford, v. 4, n. 1/2, p. 103-129, 1989.

14. LENNEBERG, E. H. Biological foundations of language. New York: Wiley, 1967.

15. MEDIN, D. L., SMITH, E. E. Concepts and concept formation. Annual Review of Psychology, Palo Alto, v. 35, p. 113-138, 1984.

16. MERVIS, C. B., ROSCH, E. Categorization of natural objects. Annual Review of Psychology, Palo Alto, v. 32, p. 89-115, 1981.

17. MILlER, G. A., JOHNSON-LAIRD, P. Language and perception. Cambridge, MA: Harvard University Press, 1976.

18. ROSCH, E. et al. Basic objects in natural categories. Cognitive Psychology, San Diego, v. 8, p. 382-439, 1976.

19. SAPIR, E. The status of linguistics as a science. In:

- Selected writings of Edwards Sapir. Berkeley: University of California Press, 1929. Existe tradução brasileira: SAPIR, E. A posição da lingüística como ciência. Trad. de J. Mattoso Câmara Jr. In: Acadêmica, 1961. - Lingüistica como ciência. Rio de Janeiro:

20. SMITH, E. E., MEDIN, D. L. Categories and concepts. Cambridge, MA: Harvard University Press, 1981.

21. VYGOTSKY, L. S. Thought and Language. Cambridge, MA: The MIT Press, 1962.

22. WHORF, B. L. Science and linguistics. In: reality. Cambridge, MA; The MIT Press, 1956. . Language, thought and

23. WITTGENSTEIN, L. Investigações filosóficas. Trad. de J. Carlos Bruni. 2. ed. São Paulo: Abril, 1975.

24. WOODFIELD, A. Schemas and protoconcepts: a two-tier model of concept formation. (Manuscrito inédito) 